INDONESIA ACCOUNTING JOURNAL

VOLUME 2, NUMBER 2, YEAR 2020

${ }^{1}$ Corresponding author

Jurusan Akuntansi

Fakultas Ekonomi dan Bisnis

Universitas Sam Ratulangi

Jl. Kampus UNSRAT

Manado, Indonesia, 95115

E-mail: welyoyorifurariani@gmail.com

${ }^{2,3}$ Jurusan Akuntansi

Fakultas Ekonomi dan Bisnis

Universitas Sam Ratulangi

Jl. Kampus UNSRAT

Manado, Indonesia, 95115

Article info:

Received 29 January 2020

Accepted 29 January 2020

Available online 29 January 2020

Keywords: regional original revenue; port levies; efforts to increase

JEL Classification: H11, H71

DOI: http://doi.org/10.3240o/iaj.27785

\section{Analisis retribusi pelabuhan dalam upaya peningkatan Pendapatan Asli Daerah (PAD) di Kota Sorong?}

\author{
Welyoyo Rifurariani ${ }^{1}$ \\ Inggriani Elim² \\ Meily Y.B. Kalalo ${ }^{3}$
}

\begin{abstract}
Regional original income is the original source of regional revenue extracted in the region which is used for the basic capital of the regional government in financing development and regional efforts to minimize the dependency of funds from the central government. Regional governments are expected to be more able to explore financial resources to the maximum, but of course in the corridor of the applicable legislation in particular to meet the needs of government funding and development in the region through Regional Original Revenue. One of them is levies from the port levies or by the name of the port service levies levied as fees for payment, anchoring services / mooring services, aviation services and scouting, dock services. This study aims to determine and analyze the increase in sea port levies to the Regional Original Revenue (PAD) Sorong City. The analytical method used in this thesis research is a descriptive method that aims at each data collected collected analyzed and drawn a conclusion and the type of research used is descriptive qualitative. Based on the results of the port levy analysis, it can be seen that during the 2011-2015 observation year, the realization of port charges on the PAD had increased quite well.
\end{abstract}

\section{Pendahuluan}

Dalam upaya menciptakan kemandirian daerah, Pendapatan Asli Daerah (PAD) menjadi faktor yang sangat penting, dimana PAD akan menjadi sumber dana dari daerah karena setiap daerah dituntut untuk meningkatkan PAD guna membiayai urusan rumah tangganya sendiri. Undang-undang yang mengatur urusan pemerintah daerah serta perimbangan keuangan antar pusat dan daerah, menetapkan pajak dan retribusi daerah menjadi salah satu sumber penerimaan yang berasal dari dalam daerah dan dapat dikembangkan sesuai dengan kondisi masing-masing daerah.

Menurut Pasal 1 angka 64 UndangUndang Nomor 28 Tahun 2009 tentang Pajak Daerah dan Retribusi Daerah yang selanjutnya disebut retribusi daerah adalah pungutan daerah sebagai pembayaran atas jasa negara atau pemberi izin tertentu yang khusus disediakan dan atau diberikan oleh pemerintah daerah untuk kepentingan pengguna.

Adapun golongan yang termasuk dalam retribusi daerah yaitu: (1) retribusi jasa umum; (2) retribusi jasa usaha; dan (3) retribusi perizinan tertentu. Mengingat pentingnya pungutan retribusi sebagai salah satu sumber PAD, maka Kota Sorong harus terus berusaha untuk mencapai target penerimaan retribusi pelabuhan yang telah ditentukan dan ditetapkan serta untuk meningkatkan pemungutan retribusi pelabuhan terhadap PAD yang dapat digunakan untuk membiayai kegiatan operasionalnya sendiri. Retribusi pelayanan kepelabuhanan dipungut retribusi sebagai pembayaran atas: (1) jasa labuh/jasa tambat; (2) jasa penundaan/pemanduan; dan (3) jasa dermaga. Sama dengan daerah-daerah lain, Kota Sorong adalah salah satu daerah otonomi yang melaksanakan pembagunan di daerah. 
Menurut Peraturan Menteri Perhubungan Republik Indonesia No. 72 Tahun 2017, tentang ketentuan umum, tentang jenis-jenis struktur, golongan dan mekanisme penetapan tarif bagi retribusi pelabuhan. Dalam Peraturan Menteri ini yang dimaksud adalah: pelabuhan laut, terminal, kapal barang, penyelenggara pelabuhan, otoritas pelabuhan, kesyabandaraan, unit penyelenggara pelabuhan, dan badan usaha pelabuhan. Kota Sorong sangatlah strategis karena merupakan pintu keluar masuk ke Provinsi Papua dan Provinsi Papua Barat juga merupakan kota industri, perdagangan dan jasa, karena dikelilingi oleh kabupaten lain yang mempunyai sumber daya alam yang sangat potensial hingga membuka peluang bagi investor dalam maupun luar negeri untuk menanamkan modalnya.

Peraturan Pemerintah No. 31 Tahun 2016 menetapkan Kota Sorong sebagai Kawasan Ekonomi Khusus (KEK) pertama di Provinsi Papua dan Provinsi Papua Barat dan sebagai pusat pertumbuhan ekonomi baru di Indonesia Timur. Seperti daerah lain Kota Sorong juga mempunyai pelabuhan laut bagi kapal penumpang dan kapal barang, yang merupakan salah satu sumber PAD Kota Sorong. Pelabuhan Kota Sorong merupakan pintu gerbang transportasi laut di Provinsi Papua dan Provinsi Papua Barat, dan diprogramkan kedepan akan menjadi pelabuhan internasional di wilayah Indonesia Timur, dalam upaya kemajuan pembangunan dan peningkatan ekonomi masyarakat Papua.

Dengan dikeluarkannya Peraturan Daerah Kota Sorong oleh DPRD beserta Walikota Kota Sorong, yaitu Peraturan Daerah Kota Sorong No. 20 Tahun 2013 pasal 3 tentang penyertaan Modal Daerah, diharapkan dapat meningkatkan PAD Kota Sorong lewat Pajak Daerah dan Retribusi Daerah. Dari hasil target dan realisasi retribusi pelabuhan laut, dapat dilihat retribusi mengalami fluktuasi setiap tahunnya, hal ini disebabkan jumlah kapal yang dibatasi masuk di pelabuhan Kota Sorong 3-4 kapal/hari dalam kurung waktu 5-10 jam /hari. Dan juga kondisi pelabuhan yang kurang luas serta fasilitas pelabuhan seperti ruang tunggu dan terminal penumpang yang pada tahun 2015 mempunyai daya tampung yang kurang memadai, bahkan tempat penumpukan peti kemas yang masih kecil.

\section{Tinjauan pustaka}

Pengertian akuntansi. Akuntansi bisa didefinisikan secara tepat dengan menjelaskan 3 (tiga) karakteristik penting dari akuntansi: (1) pengidentifikasian; (2) pengukuran; dan (3) pengkomunikasian informasi keuangan tentang entitas ekonomi kepada pemakai yang berkepentingan, (Go et al., 2013; Weygandt et al., 2011:4). Menurut Peraturan Pemerintah Republik Indonesia No. 71 tahun 2010 tentang Standar Akuntansi Pemerintahan (SAP), yang dimaksud adalah prinsip-prinsip akuntansi yang diterapkan dalam menyusun dan menyajikan laporan keuangan pemerintah. Dengan demikian, SAP merupakan persyaratan yang mempunyai kekuatan hukum dalam upaya meningkatkan kualitas laporan keuangan pemerintah di Indonesia. Akuntansi sektor publik adalah mekanisme teknik dan analisis akuntansi yang diterapkan pada pengelolaan dana masyarakat di lembaga-lembaga tinggi Negara dan departemen-departemen dibawahnya, pemerintah daerah, BUMN, BUMD, LSM, dan yayasan sosial, maupun pada proyek-proyek kerja sama sektor publik dan swasta (Bastian, 2012:6). Akuntansi sektor publik memiliki kaitan erat dengan penerapan dan perlakuan akuntansi pada domain publik yang memiliki wilayah lebih luas dan kompleks dibandingkan sektor swasta atau bisnis (Halim, 2012:10).

Pendapatan Asli Daerah (PAD). PAD dapat merujuk pada Peraturan Menteri Dalam Negeri No. 37 Tahun 2014 tentang pedoman penyusunan Anggaran Pendapatan Dan Belanja Daerah (APBD). PAD yang diperoleh dari sumber-sumber pendapatan daerah itu sendiri dipungut berdasarkan peraturan daerah sesuai dengan peraturan perundang-undangan yang berlaku (Siahaan : 2010). Menurut Undang-Undang No. 23 tahun 2014 tentang pemerintah daerah, bab 
3 pasal 6 yaitu otonomi daerah adalah hak, wewenang, dan kewajiban daerah otonom untuk mengatur dan mengurus sendiri urusan Pemerintahan dan kepentingan masyarakat setempat dalam sistem Negara Kesatuan Republik Indonesia.

Teori retribusi. Menurut UndangUndang No. 28 Tahun 2009 tentang Pajak Daerah dan Retribusi Daerah, menetapkan 30 jenis retribusi daerah yang dapat dipungut oleh provinsi, kabupaten dan kota, jumlah ini bertambah menjadi 32 jenis. Berbeda dengan pajak, retribusi pada umumnya berhubungan dengan kontraprestasi langsung, yaitu pembayaran retribusi akan menerima imbalan secara langsung dari retribusi yang dibayar (Darwin, 2010:165).

Penelitian terdahulu. Menurut Handoko (2012), penerimaan retribusi daerah selalu mencapai target yang ditetapkan, keberhasilan pencapaian target retribusi di pengaruhi oleh upaya Dinas Pengelola Retribusi. Kambu et al. (2014), menyatakan bahwa kontribusi retribusi daerah terhadap pendapatan asli daerah menunjukan peningkatan secara signifikan. Toduho et al. (2014), menyatakan retribusi belum mencapai target karena mengalami fluktuasi setiap tahunnya.

\section{Metode penelitian}

Jenis penelitian yang digunakan berupa jenis penelitian deskriptif, dimana penelitian dilakukan secara langsung dengan mendatangi objek penelitian yaitu, Dinas Perhubungan Kota Sorong untuk memperoleh data-data dan informasi yang dibutuhkan. Penelitian ini dilaksanakan pada Dinas Perhubungan dengan alamat Jl. Jenderal Sudirman Kota Sorong Papua Barat. Adapun waktu pengumpulan data meliputi kegiatan pengumpulan data dan literatur, pengelolaan data, analisis data, hingga pembahasan dan penarikan kesimpulan. Data yang digunakan dalam penelitian ini adalah data kualitatif, yaitu data berupa laporan rekapitulasi PAD Dinas Perhubungan Kota Sorong periode tahun 2011 hingga tahun 2015 dan juga data lain berupa struktur organisasi, contoh karcis masuk pelabuhan, contoh pas kecil yaitu surat ijin berlayar serta data target dan realisasi PAD Kota Sorong.

\section{Hasil penelitian dan pembahasan \\ Hasil penelitian}

Tabel 1 menunjukkan bahwa target penerimaan retribusi pelabuhan laut terhadap pendapatan asli daerah di tahun 2011 sebesar Rp. 368.000.000 direalisasikan sebesar Rp. 425.880 .000 atau sebesar 11,5\%. Pada tahun 2012 target sebesar Rp. 401.000.000 direalisasikan sebesar Rp. 356.730.000 atau sebesar 8,8\%. Pada tahun 2013, target sebesar Rp. 370.000 .000 direalisasikan sebesar Rp. 553.310.000 atau sebesar 14,9\%. Pada tahun 2014 target sebesar Rp. 407.000.000 direalisasikan sebesar Rp. 676.935.000 atau sebesar 26,99\%. Sedangkan tahun 2015 target sebesar Rp. $\quad 576.000 .000$ direalisasikan sebesar Rp. 593.380.000 atau sebesar 10,3\%.

Tabel. Target dan Realisasi Penerimaan Retribusi

\begin{tabular}{ccccc}
\multicolumn{6}{l}{ Pelabuhan Tahun 2011-2015 } \\
\hline No. & Tahun & Realisasi (Rp.) & $\begin{array}{c}\text { Target PAD } \\
\text { (Rp.) }\end{array}$ & $\mathbf{\%}$ \\
\hline 1 & 2011 & $425.880 .000,00$ & $368.000 .000,00$ & 11,5 \\
2 & 2012 & $356.730 .000,00$ & $401.000 .000,00$ & 8,8 \\
3 & 2013 & $553.310 .000,00$ & $370.000 .000,00$ & 14,9 \\
4 & 2014 & $676.935 .000,00$ & $407.000 .000,00$ & 14,9 \\
5 & 2015 & $593.380 .000,00$ & $576.000 .000,00$ & 10,3 \\
\hline \multicolumn{5}{l}{ Sumber: Olab data, 2019}
\end{tabular}

\section{Pembahasan}

Pendapatan Asli Daerah (PAD) merupakan sumber penerimaan daerah yang asli digali di daerah, yang digunakan untuk modal dasar pemerintah daerah dalam membiayai pembangunan dan usaha-usaha daerah untuk memperkecil ketergantungan dana dari pemerintah pusat. Sumber-sumber PAD terdiri dari : pajak daerah, retribusi daerah, hasil pengelolaan kekayaan daerah yag dipisahkan, dan lain-lain pendapatan asli daerah yang sah. Retribusi daerah terbagi atas beberapa jenis yaitu; (1) Retribusi jasa umum; (2) retribusi jasa usaha; dan (3) retribusi jasa perisinan tertentu.

Retribusi pelayanan kepelabuhan termasuk dalam jenis retribusi jasa usaha. Retribusi Kepelabuhan atau dengan nama Retribusi Pelayanan Pelabuhan dipungut 
retribusi sebagai pembayaran atas; (1) jasa labuh/jasa tambat; (2) jasa penundaan dan pemanduan; dan (3) jasa dermaga. Retribusi pelabuhan laut adalah retribusi yang dikelola oleh Dinas Perhubungan, yang kemudian hasil pungutannya akan diserahkan kepada Dinas Pendapatan Asli Daerah, sebagai salah satu sumber Pendapatan Asli Daerah di Kota Sorong.

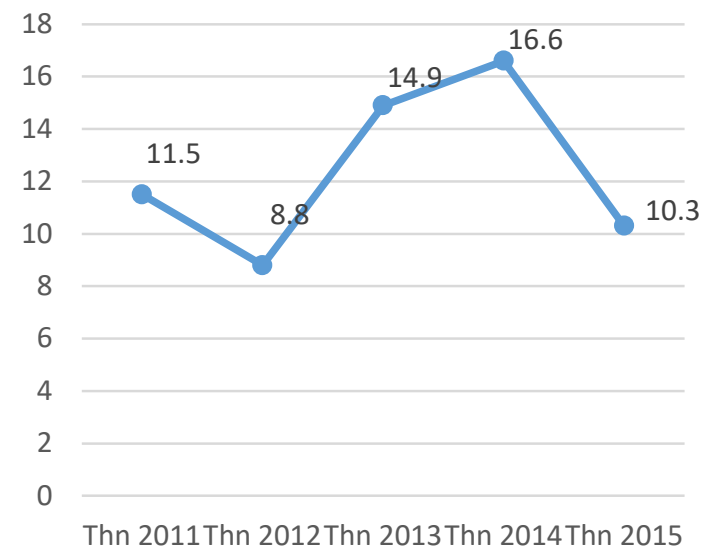

Gambar 1. Grafik Penerimaan Retribusi Pelabuhan Kota Sorong

Sumber : Dinas Perhubungan Kota Sorong, 2019

Gambar 1 menunjukkan bahwa retribusi pelabuhan mengalami fluktuasi setiap tahunnya, dimana pada tahun 2011 besar penerimaan retribusi pelabuhan $11,5 \%$ atau sebesar Rp. 425.880.000. Pada tahun 2012 retribusi pelabuhan mengalami penurunan sebesar 8,8\% atau sebesar Rp. 356.730 .000 disebabkan karena kurangnya kapal yang sandar di pelabuhan Kota Sorong karena jumlah kapal yang sandar hanya sekitr 3-4 kapal/hari dalam kurung waktu 5-10/hari. Pada tahun 2013 besar retribusi pelabuhan mengalami kenaikan sebesar $14,9 \%$ atau sebesar Rp. 553.310.000.

Meningkatnya jumlah retribusi pelabuhan ini karena area pelabuhan yang semakin diperbesar seperti dermaga kapal, terminal penumpang dan lapangan peti kemas hingga jumlah kapal yang sandar bisa lebih banyak dari tahun sebelumnya. Pada tahun 2014 retribusi kembali meningkat sebesar 16,6\% atau sebesar Rp. 676.935.000. Selain area pelabuhan yang di perluas, Kota Sorong juga mempunyai tempat-tempat wisata yang menarik, dan yang dapat menarik wisatawan dalam negeri maupun luar negeri, salah satunya destinasi wisata di Kota Sorong adalah Kabupaten Raja Ampat. Semakin banyak pengunjung yang datang ke Raja Ampat maka arus penumpang semakin besar, maka fasilitas pelabuhan banyak digunakan dan ini memberikan masukan bagi pungutan retribusi pelabuhan yang cukup besar. Dan pada tahun 2015 retribusi pelabuhan mengalami penurunan menjadi $10,3 \%$ atau sebesar Rp. 593.380.000. Penurunan ini disebabkan karena semakin banyak tempat wisata di daerah lain membuat pengunjung Kota Sorong berkurang.

\section{Kesimpulan dan saran Kesimpulan}

Kesimpulan dari penelitian ini adalah:

1. Berdasarkan hasil analisis retribusi pelabuhan dapat diketahui bahwa selama tahun 2011-2015, realisasi terbesar retribusi pelabuhan terhadap PAD terjadi pada tahun 2014 yaitu Rp. 676.935.000 dari target sebesar Rp. 407.000.000 atau sebesar $16,6 \%$ dan pada tahun 2013 yaitu Rp. 553.310.000 dari target sebesar Rp. 370.000 .000 atau sebesar $14,9 \%$.

2. Retribusi pelabuhan mengalami fluktuasi dalam beberapa tahun, ini karena jumlah kapal yang masuk kepelabuhan Kota Sorong dibatasi 3-4 kapal/hari dalam kurun waktu 5-10 jam/hari, jika ada 6-8 kapal yang sandar dalam kurun waktu 5$10 \mathrm{jam} /$ hari, maka otomatis retribusi akan meningkat, ini disebabkan karena dermaga pelabuhan sorong yang tidak cukup menampung jumlah kapal yang lebih banyak.

3. Upaya yang dilakukan oleh Pemerintah Kota Sorong adalah memperbesar pelabuhan seluas 5 hektar, pengerasan dan penimbunan lapangan, pengembangan lokasi tumpuk peti kemas 5 haktar, serta pembangunan dermaga 250x30 $\mathrm{m}^{2}$ dengan kedalaman 16 MLWS. Melalui pekerjaan tersebut kapasitas terminal peti kemas di pelabuhan Kota Sorong yang awalnya hanya 50.000 TEUs telah ditingkatkan 
menjadi 350.000 TEUs per tahun dan pelabuhan Kota Sorong yang awalnya tidak melayani pelayanan domestik dan internasional kini, sudah dapat melayani 4 (empat) pelayanan domestik dan 1 (satu) pelayanan internasional.

4. Hasil analisis menunjukkan bahwa retribusi pelabuhan adalah salah satu sumber PAD bagi Kota Sorong dan memberikan kontribusi cukup besar.

\section{Saran}

Saran bagi Dinas Perhubungan Kota Sorong adalah:

1. Dinas Perhubungan Kota Sorong perlu menggunakan teknik analisis data yang digunakan dalam penelitian ini yaitu menganalisis jumlah retribusi yang diterima agar dapat mengetahui fluktuasi penerimaan dan sebab akibat penurunan dan peningkatan retribusi pelabuhan terhadap PAD.

2. Pemerintah Kota Sorong perlu memperluas lahan utuk peti kemas, dermaga dan pelabuhan agar jumlah kapal yang datang bisa mencapai 6-8 kapal/hari dalam kurung waktu 5-10 jam/hari sehingga jumlah retribusi pelabuhan yang didapatkan akan meningkat lebih besar.

3. Pemerintah Kota Sorong juga perlu menambah fasilitas pelabuhan seperti terminal pelabuhan dan lahan parkir, jika kapal yang masuk ke pelabuhan Kota Sorong mencapai 6-8 kapal/hari dalam kurung waktu 5-10 jam/hari, jumlah penumpang yang datang dan berangkat akan meningkat, maka fasilitas pelabuhan seperti terminal dan lahan parkir harus diperluas.

4. Pemerintah Kota Sorong perlu menyediakan berbagai fasilitas yang dapat menunjang peningkatan penerimaan retribusi pelabuhan sesuai dengan keadaan dan kondisi pelabuhan di Kota Sorong.

\section{Daftar pustaka}

Bastian, I. (2012). Akuntansi sektor publik, Edisi 3. Jakarta: Penerbit Erlangga.

Darwin. (2010). Pajak Daerah dan retribusi daerah. Jakarta: Penerbit Mitra Wacana Media.
Go, E. R., Sondakh, J., \& Wokas, H. (2013). Analisis penerimaan retribusi parkir Kota Manado tahun 2008-2012. Going Concern : Jurnal Riset Akuntansi, $8(3)$, 26-36. https://doi.org/10.32400/gc.8.3.25098.2013.

Handoko, A. T., (2012). Analisis perkembangan retribusi pasar daerah sebagai sumber pembiayaan otonomi daerah di kabupaten pemalang tahun 2007-2011. Economics Development Analysis Journal, 1(2), 1-7. https://journal.unnes.ac.id/sju/index.php/edaj/ article/view/470.

Halim, A. (2012). Akuntansi keuangan daerah, Edisi 4. Jakarta: Penerbit Salemba Empat.

Kambu, S. S., Rotinsulu, D. Ch., \& Tumangkeng, S. Y. I. (2015). Kontribusi pajak dan retribusi daerah terhadap pendapatan asli daerah kabupaten Sorong. Jurnal Berkala Ilmiah Efisiensi, 15(3), 1-14. https://ejournal.unsrat.ac.id/index.php/jbie/arti cle/view/8594.8167.

Peraturan Pemerintah Republik Indonesia No. 71 tahun 2010 tentang standar akuntansi Pemerintahan (SAP).

Peraturan Menteri Perhubungan Republik Indonesia No. 72 Tahun 2017 tentang Jenis, Struktur, Golongan Dan Mekanisme Penetapan Tarif Jasa Kepelabuhanan.

Peraturan Menteri Dalam Negeri No. 37 Tahun 2014 tentang Pedoman Penyusunan Anggaran Pendapatan dan Belanja Daerah (APBD).

Peraturan Daerah Kota Sorong No. 20 tahun 2013 tentang Penyertaan Modal Daerah.

Peraturan Pemerintah No. 31 Tahun 2016 tentang Kawasan Ekonomi Khusus Sorong.

Siahaan, M. P. (2010). Pajak daerah \& retribusi daerah, berdasarkan Undang-Undang No.28 Tahun 2009 tentang pajak daerah dan retribusi daerah, Edisi Revisi 2010. Jakarta: PT Raja Grafindo Persada.

Toduho, D. A. M., Saerang, D. P. E., \& Elim, I. (2012). Penerimaan retribusi pasar dalam upaya meningkatkan pendapatan asli daerah Kota Tidore Kepulauan. Jurnal EMBA: Jurnal Riset Ekonomi, Manajemen, Bisnis dan Akuntansi, 2(2), 1090-1103. https://ejournal.unsrat.ac.id/index.php/emba/a rticle/view/4501.

Undang-undang No. 28 tahun 2009 tentang Pajak Daerah Dan Retribusi Daerah.

Undang-undang No. 23 tahun 2014 tentang Pemerintah Daerah.

Weygandt. J. J., Kimmel. P. D., \& Kieso. D. E., (2011). Financial accounting, IFRS Edition. United State: John Wiley \& Sons, Inc. 